\title{
An Analysis of the Language Used To Communicate Information on Climate Change
}

\author{
Peter Makwanya. \\ Department of Communication and Media Studies. Zimbabwe Open University. Zimbabwe.
}

\begin{abstract}
This article analyzed the language used to communicate information on climate change. The discourse of climate change is not inclusive of the majority of people of the Sub Saharan region with specific reference to Zimbabwe. This is due to its technical and ambiguous nature. A variety of scientific documents, magazines, technical journals and briefings were analyzed. The methodology of Critical Discourse Analysis (CDA) and Document Analysis were used to analyze various texts in order to uncover the possible hidden meanings of a variety of linguistic aspects. It was noted that linguistic aspects like metaphors of fear and panic, hedging techniques and compounding are frequently used. Climate change communication is loaded with technical jargon which places the ordinary people, particularly in Zimbabwe in a dilemma. For that reason the climate change discourse creates information and knowledge gaps between those from the developed countries and the developing countries. Interviews were administered on policy makers, environmentalists, educationists and other stakeholders. Qualitative data was analyzed using grounded theory to describe and explain the elicited responses from stakeholders in order to complement data from textual analysis. It is recommended that there should be a lot of media awareness, education and training on climate change issues in Zimbabwe. The government of Zimbabwe, the private sector and NGOs should develop training programmes to communities in indigenous languages which are relevant to their needs. Issues of ideologies are also quite prevalent in climate change communication.
\end{abstract}

Key Words: Climate, Climate Change, Global Warming, Weather, Green House, Carbon

\section{Introduction}

This study is in the area of sociolinguistics, which according to Herbert (1992) is the social study of linguistic diversity and how linguistic differences reflect social differences. It is a discipline that studies language in relation to what happens in society. Climate change communication appears to sideline the majority of people through the use of technical and ambiguous language. The majority of these people, mainly the poor and vulnerable who live in the Sub Saharan Africa and in this regard, Zimbabwe is no exception. The dilemma which the discourse of climate change causes is seen as the creation of the scientists in the developed countries whose main agenda is gate keeping of knowledge. The technicalities and ambiguities of scientific language place African readers in complex situations as they are forced to tackle scientific concepts which are mainly foreign to them using local languages for interpretations. The readers have two things to do; first, they will be expected to try and translate the knowledge acquired in a technically loaded jargon into their first languages; secondly, the readers will be expected to apply the language to their own situations. It would appear as if the readers cannot understand their own world without understanding the European situation first (Hadebe (1997) in Chivaura and Mararike, 1998).These sentiments highlight dangers associated with climate change communication and they have to be nipped in the bud but those responsible may not succeed if the language used to communicate climate change issues becomes an impediment or a barrier itself.

There are two things that contribute to the likely catastrophes to befall Africa which are the lack of resources and incentives to motivate them for adaptation and failure to adapt to the technical nature of language used to communicate information on climate change. The people of Sub Saharan Africa, Zimbabweans included need to understand this jargon as they are also stakeholders in attempts to fight climate change. The scientific writers need not continue imposing their technical language on the unsuspecting and unwilling audiences. The indigenous people best understand information in their mother tongue and to continue talking to them in unfamiliar discourse would create an understanding gap ending up-stalling the mitigation and adaptive efforts that are needed in this process.

\section{Background To Climate Change}

In 1827, Frenchman Jean Baptiste Fourier in Borchert (2007) was the first to use the green house analogy to explain how the earth is kept warmer than otherwise. During the 1890sSwedish scientist, Svante Arrhenius together with Thomas Chamberlain concluded that human activities could warm the earth by increasing the amount of carbon dioxide in the atmosphere. When the first UN Conference on Human 
Environment was held in Stockholm in 1972, there was some acknowledgement of the issue of climate as a possible problem in years to come by. In 1988, the Intergovernmental Panel on Climate Change (IPCC) was set up to assess and synthesize the latest scientific, technical and socio economic literature on global warming (Toulmin, 2009). It operates under the auspices of the World Meteorological Organization (WMO) and the United Nations Environmental Programme (UNEP).The IPCC does not carry out research, but collaborates with hundreds of scientists and experts around the world, as well as governments. It has produced Four Assessment reports, in 1990, 1995, 2001 and 2007. The IPCC's latest report of 2007 states that, warming of the climate system is unequivocal, as is now evident from observations of increases in global average air and ocean temperatures, wide spread melting of snow and ice and rising global average sea level (IPCC, 2007). Dow and Downing (2007) offer the same views by saying; the climate has been completely thrown out of kilter and each day brings fresh proof: more frequent and more violent cyclones in the Caribbean, floods in Africa and the melting of glaciers. These sentiments testify to how climate change is wrecking havoc and inflicting untold suffering to humanity around the world.

\section{Climate Change In Africa}

Africa is one of the most vulnerable continents to climate change and climate variability, a situation aggravated by the interaction of 'multiple stresses', occurring at various levels, and low adaptive capacity. Changes in a variety of ecosystems are already being detected, particularly in Southern African ecosystems, at a faster rate than anticipated (Boko et al, 2007).Climate change is the only one of many powerful forces affecting African development prospects. There is evidence of change in temperature and the damaging effects of changing rainfall patterns throughout Sub Saharan Africa. Global warming has affected water availability, with some areas becoming much drier and others much wetter. Africa's share in terms of climate change comes in the form of its wanton destruction of its forests (deforestation).Africa's deforestation accounts for $20 \%$ of the world's green house emissions (Dow and Downing, 2007). With the discovery of mineral resources such as coal in South Africa, oil in Sudan and Uganda, as well as diamonds in Zimbabwe, thousands hectors of forests would be destroyed. The exceptional floods that hit many parts of Africa in September 2007 are a reminder that too much water can be a problem; the same applies to too little water and Mozambique is always a victim of these floods every year. There are still prospects of more frequent extreme weather events such as droughts, floods and storms, as heating of the global atmosphere drives a more active and moisture-laden weather system. This is echoed by Dr.Maathai, the 2004 Nobel Peace Prize winner in Toulmin (2007) has the following assertion:

\section{Africa is the continent that will be hit hardest by climate change. Unpredictable rains and floods, prolonged droughts, subsequent crop failures and rapid desertification,...global warming activities, have in fact already begun to change the face of the earth}

At present, the rules for addressing climate change are being written by the powerful and polluting nations and as a result the deal they reach among themselves will pay particular attention to their interests (Toulmin, 2009). This leaves the African countries that are likely to be hit hard by climate change with little or no voice. This also leaves the Africans without a language and voice of their own in climate change issues since the developed countries even write for the Africans on issues concerning climate change. It is because of this reason that the thrust of this study is on analyzing the language used to communicate climate change information so that the results will be used to come up with the language that is readable, relevant, and simple as well as being understood by the grass roots.

\section{Climate Change In Zimbabwe}

The devastating droughts of 1992 and the floods of 2002/3 were clear testimonies that climate change was taking its toll in Zimbabwe. The shifting of seasons and erratic rain fall patterns or more than the required amounts of rainfall became clear evidence that climate change was indeed with us. The drought of 2007/8 is a case in point. Climate change information in Zimbabwe remains quite abstract and elitist in the eyes of the ordinary, who in this case are the majority who can read but cannot understand the technical language of climate change. The problem seems to have come about a long time ago when climate change information used to be communicated as a scientific problem that needed scientific solutions. Because of that the majority of people ended looking up to scientists for salvation that never came.

Since scientists cannot communicate issues to the people in a simple manner, they tend to communicate in powerful technical jargon that raise alarm and panic in readers who lack knowledge of climate change issues as well as the enthusiasm to fight it. The absence of intensive media campaign on climate change issues in Zimbabwe and other African countries appears to continue to keep people in the dark on this very important issue. A critical analysis would reveal that, climate change discourse is not classified as a juice beat. That is, the 
type of news that doesn't need urgent attention or news that don't sell quickly. The majority of African leaders are preoccupied with fighting the return of imperialism instead of other issues like climate change. For this reason, people need information but they are starved of it, by the media and the leaders lack comprehensive knowledge and training on climate change.

For Zimbabweans to participate fully in the fight against climate change, they have to understand what it is all about and should know how their lives are in danger from climate change so that they would respond effectively. Zimbabweans have the knowledge of floods, violent winds, extreme heat, carbon emissions, droughts, unpredictable weather and deforestation but they cannot link these to climate change (Environmental Management Authority (EMA) 2010).Rural Zimbabweans, in particular farmers and participants in NGO projects cannot understand the continued use of foreign language and technical jargon to communicate their experiences especially when they have indigenous knowledge of their environment. It is the duty of the media to link what is happening in the environment to climate change so that they inform people accordingly.

Since the area of climate change is quite topical and controversial, a number of researches have been carried out in this area in Zimbabwe. Dhewa (2007) carried out a research in the area of science and technology communication, entitled; 'Indigenous African knowledge has much to offer science, but only if science can be translated in local languages'. Dhewa's wish is to translate science and technology discourse into Ndebele. This appears quite a noble idea since work on the Ndebele dictionary is complete. The document would indeed provide the most needed insight into his project. The relationship between Dhewa's research and this article is that both of us agree that scientific discourse is not understood by the majority, who in this case are stakeholders such as farmers and the vulnerable groups participating in NGO projects and they are supposed to make use of the language in a variety of contexts for development communication, adaptation and mitigation purposes. Farmers need climate change information in local languages in order to interpret the state of weather so that they plan appropriately. Rural communities participating in NGO programmes need this kind of communication so that they participate effectively in conservation and greening activities.

Authors of climate change discourse thrive on the use of metaphors that instill fear, panic and surprise, hedging techniques, compound words as well as ideologies of construct. Aristotle as cited in Eubanks (1999) views a metaphor as a two part expression, which has two main discursive locations, namely, the place where it has originated and the place to which it has been transferred. To this writer's view, the communication dilemma realized from the use of metaphors, come as a result of Levinson (1983)'s context of situation which has to appeal to both discursive locations. This appears to be the problem with the metaphors of climate change which scientists are comfortable with while they are a nightmare to the majority around the world, especially in Sub Saharan Africa. The local and indigenous languages are readily available and the people use those languages to interact with the environment as well as having a close relationship with it.

The use of hedging techniques is quite prevalent and inherent in the climate change discourse. Mathew (1997) views hedging as, linguistic devices by which speakers avoid being compromised by statements that turn out to be wrong or requests that are not acceptable. Van Dijk (2000) perceives hedging as the tone of doubt or uncertainties' due to the user of such words as: may, could, likely and sometimes. The listed words are modal verbs that scientific writers use in order to be cautious about the way they communicate. Gethaiga in Chivaura and Mararike (1998) asserts that language, especially the 'mother tongue' is the basis of all learning and culture transmission of knowledge and that those who do not value their languages and cultures do not respect themselves and cannot, therefore expect others to respect them.

Dow and Downing(2006) view compounding as a lexical combination of at least two roots such as 'global warming', 'green house effect', 'human activity', 'fossil fuels', 'water harvesting', or 'water accounts'. The other technique scientists' use to come up with compound words as suggested by Keller (2000) is studying around lexical creativity around carbon compounds in order to come up with the following examples: 'carbon finance', 'carbon foot print', or 'carbon sinner'. The idea of impersonating the word 'carbon' is designed to help shape public attitudes and perceptions on issues about climate change but that particular public need to be able to comprehend this kind of discourse before they can be creative or change their attitudes. Environmental communication affects everybody, therefore it needs to be relevant and context specific to everyone concerned.

\section{Statement Of The Problem}

There are hidden linguistic meanings behind the scientific discourse of climate change as well as the linguistic and knowledge gaps between the technical nature of scientific language and the assumed knowledge of the indigenous people of Sub Saharan Africa, particularly Zimbabwe.

\section{Purpose Of The Study}

Though this article's main thrust is to critically analyze the language used to communicate climate change, the major issue is to establish whether non-indigenous languages are communicating successfully issues 
that have to do with climate change communication or not. Hence there must be a paradigm shift to try and consider indigenous languages when communicating climate change information.

\section{Methodology Of Data Gathering}

The methodology is mainly qualitative in nature. The data for this study is document based, it is found in scientific journals, magazines, pamphlets and other technical scientific writings. This is the data that is being critically analyzed so as to come up with hidden meanings behind the discourse of climate change. The methodologies that form the bedrock of this research are document analysis, text analysis and unstructured interviews. The approach that will dominate the critiquing of scientific documents, texts and other technical writings is Critical Discourse Analysis (CDA).

\section{DOCUMENT ANALYSIS}

Hoepful (1997) asserts that another source of information that can be invaluable to qualitative research is document analysis. Document analysis involves exploring or analyzing documents on a particular subject or topic in order to establish certain recurring themes or features. Such documents might include official records, magazines, journals, reports, pamphlets and diaries. In making use of document analysis, the researcher obtained some magazines, pamphlets and books on climate change from the Climate Change office in Harare. The researcher then used Critical Discourse Analysis (CDA) to study some of the selected texts from the magazines and text books so as to carry out this study.

\section{CRITICAL DISCOURSE ANALYSIS}

As noted by Dellinger (1995), Critical Discourse Analysis (CDA) has made the study of language an interdisciplinary tool used by scholars from a wide range of fields such as anthropology, sociology, communication, sciences and linguistics. Dellinger (Ibid) contends that CDA has an overtly political agenda as it aims to provide a better understanding of socio-economic and cultural aspects of the texts. These texts are then produced by socially situated speakers and writers. Fairclough (2000:104) concurs with Dellinger as follows:

Critical Discourse Analysis is an inter-disciplinary approach to the study of

discourse which views language as a form of social practice, also focuses on

various ways in which social and political domination is produced through

text and talk.

The major objective of CDA is to uncover the ideological assumptions that are hidden in written words, oral speech or pictorial communication. If one looks closely at the discourse of climate change, it is quite clear that there are ideological stand points and issues about 'US' and 'THEM' are highly prevalent. That is 'US', in the developed countries who know how to look after the environment and 'THEM', in developing countries who are not able to manage their environment properly. Fairclough (2000) reveals that CDA unmasks hidden meaning so as to make everything clear. For this reason, a sound knowledge of CDA makes it possible for the readers to unravel the grey areas in the discourse of climate change. In this view, critical discourse analysis seeks to demystify and deconstruct the myths surrounding climate change communication.

It is important to employ the use of CDA when analyzing the language for communicating information on climate change due to the following reasons:

i) CDA attempts to acknowledge that authentic texts are produced and consumed not in isolation but in real world contexts with all their complexities. In this view CDA is highly context specific.

ii) CDA is a highly integrated form of discourse analysis in that it tries to unite at least three different levels of analysis which are: document, textual and social analysis. Philips and Jorgensen (2004) view CDA as an interdisciplinary perspective which combines textual and social analysis.

iii) CDA is very much concerned with important societal issues. While 'context' is meant to include not only the immediate environment in which texts are produced and interpreted but also the larger societal context including its relevant cultural, political, social inequalities, non-democratic practices and other injustices in attempting to spur readers to corrective action.

iv) CDA does not only describe unfair social/political practices but is critical of them. In this view, it is the ideological belief by scientific authors from the developed countries that, indeed, it is their duty to communicate to the developing countries while they are passive listeners yet the same people are supposed to be active participants in the fight against climate change.

\section{Unstructured Interviews}

On the sidelines of the climate change training workshops attended by this researcher in December 2010 and January 2011 respectively, the researcher interviewed Climate change experts and an academic and a social commentator from the English department of the University of Zimbabwe. The bone of contention was the complexities regarding the language used to communicate information on climate change. They all shared 
similar sentiments that the technical nature of the language of climate change is quite a stumbling block whether one is learned, literate or illiterate.

The Director of Climate Change in Zimbabwe also noted that scientists have difficulties in communicating to the rest of the readers and the generality alike. He went on to emphasize that scientists need to simplify their nature of communication so that the majority of people would understand.

A researcher with the UNDP was interviewed by this researcher and also emphasized that, farmers in Chiredzi have been clamoring for information written in the language that they can read and understand. He also pointed out that, it was difficult to do a translation from the complex scientific discourse to local languages but said that; with the published dictionaries in Shona and Ndebele, it is the duty of the academics in universities to venture into the project of translating the discourse climate change into vernacular.

A professor in the English department at the University of Zimbabwe also urged the scientists to take into account the issue of Indigenous Knowledge System when ever they are communicating to Africans. He also highlighted that, "we need to have the equivalent of the green color in our vernacular and its called 'Pfumvudza'.

Mary Price, a climate change journalist and trainer said, "Language is all". She said anybody who is going to come up with the appropriate language for communicating information on climate change will indeed be a hero.

\section{A Critical Discourse Analysis Of Hedging Techniques In Climate Change Discourse}

Climate science involves scientific uncertainties therefore scientists use hedging techniques as they do not have $100 \%$ confidence in their climate change projections as shown in the following examples: may, could, likely or sometimes.

I. part of Cape Town may be covered with water in fifty years to come.

Ii. increases in temperature and evaporation in the tropics could change the timing and intensity of the monsoons.

Iii. flooding, a likely outcome of climate change in many parts of the world brings a variety of health challenges sometimes contaminate water supplies.

The use of ' $\boldsymbol{m a y}$ ' is to indicate the degree of uncertainty, that, in some time to come, in not too distant future, the whole of Cape Town 'may' or 'may not' be submerged by water. Behind the scientists' assertion, the word ' $m a y$ ' has been used to indicate both the positive and the negative. In this view climate change scientists have used the lexical item 'may' to show that, they are not completely sure about their pronouncements or that, because the subject climate change is such a complex one, they also do not have complete knowledge about how climate change works. By using 'may', climate change scientists appear to be toning down their statements so as to minimize conflict. For this reason, Fand (1990) in Salager-Meyer (1994) describes scientific hedges as associated with imprecision thereby regarding them as linguistic cues of bias used to avoid accountability or stewardship of the environment. Above all, there is the issue of allegiance, which they always expect readers and academics to adhere to. Although scientists use a variety of hedging techniques; they always want to retain ownership and omnipotence of the information.

Scientists' use of 'may' can be classified according to Levinson's (1983) polite strategies as modes of addressing people. Myers (1998) argues that hedges are better understood as positive or negative strategies used to mitigate two central positions expressed in scientific writing. At the same time scientific hedges fall short of Grice (1970)'s Maxims of quality and manner. According to Grice's Maxims of quality, climate change information lacks absolute truth as it is not specific, clear and concise. Climate change discourse lacks autonomy and appropriateness. Although the use of hedging is prevalent in the indigenous languages, it is best understood and contextualized in those situations rather than being communicated in isolation as scientists do.

The use of 'likely' by the scientists is to indicate the probabilistic nature of the unfolding manner of climate change processes. The following is an example:

$$
\begin{aligned}
& \text { flooding, a 'likely' outcome of climate change in many parts of the world, } \\
& \text { brings a variety of health challenges or 'sometimes' contaminates water supplies. }
\end{aligned}
$$

The lexical item, 'likely' is a modal adjective used to denote the probability or the likelihood in the occurrence of floods in many parts of the world. It is true, from the scientists' perspectives and products of their research that, after heavy rains and violent winds, the act of flooding is 'likely' to manifest itself. What the scientists are not able to tell us are the exact dates in which these floods will take place but it might also be very much unlikely that these floods will ever take place. As a result of these assertions, it appears that scientific 
communication remains mostly guess work until and unless the outcome occurs. These outcomes like floods are quite destructive because people will not be prepared for them or they will be lacking appropriate information to mitigate climate change effects.

When these floods finally wrack havoc, 'sometimes' they contaminate water supplies and bring health challenges. The use of the lexical item 'sometimes', which is an adjectival term of time is meant to articulate the passage of time that, depending on various times and seasons heavy rains may bring health challenges or contaminate water. A closer analysis would reveal that it is not always certain that heavy rains do bring with them health challenges, 'sometimes' they do but 'sometimes' they do not. In this view, and depending on the outcome, that is when the assertions become a reality. For this reason, climate change communicators can only speculate about future disasters but they are always not sure about the exact dates and people will have to come to terms with these dates when they are already in trouble.

\section{A Critical Discourse Analysis Of Metaphors Used To Communicate Information On Climate Change}

Scientists use metaphors that end up confusing people as well as instilling fear or panic. They use these metaphors' to separate themselves from the larger audience since they want their field to remain a closed area as well as for gate-keeping purposes. The roles of scientific metaphors as tools of communication are to try and conquer the unknown as they have direct impacts on the peoples' ways of interacting among themselves as well as with their environment. Besides being conventionalized, these metaphors do not lose their political power. The following metaphors are going to be critically analyzed in order to bring out the hidden intentions of the scientific writers'.

\section{Green House}

To begin with, in Zimbabwe we do not have an acceptable equivalent of the green colour in our indigenous languages (Shona and Ndebele).Some societies refer to the green colour as 'pfumvudza' (a mixture of green shoots and red leaf shoots on trees) whilst other communities refer to the green color as 'kusvibira' (loosely translated to refer to the green colour). It is important to begin to critically analyze the relevance of the green house in Zimbabwe. This is because the concept of green house remains back grounded by the scientists' for a long time. How green is the green house? If we are to simplify the term green house into simple English, we could possibly say: market gardening or plastic covered gardens would be more appropriate. Literally, we associate the green colour with nature, vegetation, life and farming but because of climate change, people are now forced to associate the favorable colour with danger or disaster. The dilemma comes about as people would try to place this metaphor into context. Due to the idea that most of us think in our local languages before we can translate the concept into English is itself a dilemma for the majority of the people.

The extension of the metaphor 'green house' brings us to its associated terms like, green house gases which are not necessarily green but they are described as green house gases. This further confuses the people and these gases are carbon dioxide, methane and nitrous oxide. It is also difficult for the people to associate the greenhouse gases with the colour green if at all they know them or even if they can associate their anthropogenic behaviors with the climate change.

\section{Carbon Footprints}

Literally the concept of footprints brings out the image of a pair of feet, bare feet being displayed or living out some marks on the ground. A deeper analysis of the concept of 'carbon footprints', unravels the issue of leaving out permanent marks of carbon by foregrounding the process of discharging industrial waste into the rivers, throwing plastics all over, burning coal, deforestation and defacing of the earth's surface as well as farming in wetlands. A combination of lexical creativity around the word carbon together with compounding process is modeled around the morals and attitudes of people. The term 'carbon footprints' is aimed at correcting the human activity or behaviors' which have contributed so much to the increase of carbon into the atmosphere.

\section{Catastrophe}

In climate change discourse, the word catastrophe spells out, destruction and terror or an unpleasant happening like a disaster or a volcanic eruption, mudslide, or a tsunami. The term 'catastrophe' has been fore grounded so as to show the impact of a destructive happening. This is according to Grice's Maxims of manner and quality which specifies the amount of possible damage as well as the likely impact to be inflicted on the environment. But according to media analysts such as the BBC, the term catastrophe can be used as a hyperbole effect, for exaggerative processes in order to scare people. This is due to the fact that, the term 'catastrophe' is quite pervading in nature and as a result it builds grim mental images in the minds of the people. Because of the magnitude of the damage which is likely to cause, it unsettles people and they will continue to be pessimistic and live in fear. As a result of this fear, people will not participate freely in adaptation programmes. 


\section{Disaster}

The lexical term 'disaster' has been nominalised. It has been rather turned into a noun. Scientists normally use this term for speculative or topicalisation purposes in order to fore ground the likely magnitude of the impending disaster. In Asia and Africa, the lexical item 'disaster' is the last they would want to hear of, as it brings back memories of Cyclone Elaine, Japheth or Tsunami disasters. For this reason, when scientists refer to the impact of climate change as disastrous, they will be instilling an element of panic in people. People are more comfortable with the word danger as it is a bit common and malleable in use and in deed. A critical analysis of superlatives would reveal that, from the linguists' point of view, the word danger occupies the least threatening slot when compared to the expressions 'more dangerous' and 'most dangerous.'

\section{A Critical Discourse Analysis Of Compounds Used To Communicate Climate Change}

The use of compounding is quite inherent in climate change discourse. In fact, the bulk of scientific discourse and in particular climate change information is characterized by a variety of compounds modeled around several clusters spelling out moral and religious clusters, dietary clusters, or financial clusters. In climate change communication, the lexical creativity of compounds revolves around the word carbon because it is the root of excess carbon that causes global warming. The following carbon compounds fall under the following carbon clusters: moral and religious cluster (carbon sinner, carbon guilty, or carbon criminal) a dietary cluster (low carbon diet, carbon calories) financial cluster (carbon trading, carbon finance, or carbon markets). The contextual information that these carbon compounds have is going to be spelt out in the following forms of analysis:

\section{Carbon Sinner}

This is classified under the moral and religious cluster and it appears to be directed to countries who are major polluters of green house gases as well as multinational companies who emit a lot of carbon and methane into the atmosphere. Countries, notably, the USA, China, India, Australia and Russia are seen as Carbon Sinners. They became sinners as a result of not honoring climate change protocols and roadmaps designed to lower the green house emissions. The discourse of sin is used to try and regulate the moral and ethical aspects within emitting countries and individual multinational companies like Coca Cola, Union Carbide, Shell, Texaco and Total, just to cite a few. Climate change scientists use sin as a biblical allusion in an attempt to make major emitting countries to feel guilty and be accountable at the same time.

These countries have not only sinned against God alone but they have also sinned against the generality of citizens around the world. For that reason, they owe these people not only an apology but also compensation for loss of lives and destruction of property. The most worrying issue in this polluting discourse is that, people and nations around the world have never been told the nature of punishment that would be meted to those who are guilty of emitting dangerous gases into the atmosphere. We only hear about these countries being castigated, trashed and mocked but still what is going to happen to them remains a mystery and the whole world needs to know.

\section{Carbon Sink}

There are two things involved in carbon. Apart from being a harmful gas, carbon is also very useful in forests and underground eco-life. Forests absorb carbon dioxide and release the oxygen that we all breathe. Before taking a deeper analysis into the activities of carbon sinks, it is also important to note the complexity the lexical item, 'carbon sink' poses to the readers of climate change information. It is a term that needs clarity and conciseness. The words, 'forest-preservation' or 'forest farming' may be very much appropriate. This is because when we preserve forests and plant more trees together with preserving wet-lands we will be keeping carbon locked under the ground. If we unlock carbon that is under the ground, it will be released in the atmosphere thereby ending up overheating the atmosphere and the ozone-layer. If the earth is severely warmed that's when countries will witness droughts, erratic rainfall patterns over-heating and diseases (Dow and Downing 2007).

What should a developing country like Zimbabwe, desperate to develop and boost its economy do after discovering large deposits of diamonds?

The answer is simple; developing countries should try to come up with developmental projects that help to restore the cleared forests around the mining areas.

\section{Carbon Markets/Trading}

This falls under the financial cluster and it is designed to promote what is called the Clean Development Mechanism (CDM). These are programmes in which developing countries are paid for conserving their forests or acquire rights to sell their carbon to the developed countries. As a developing country, how many people are into this confusing discourse of carbon markets/trading? Although Zimbabwe may want to go green 
just like other countries, it is quite clear that the discourse of carbon markets or trading is out of reach of many Zimbabweans and also not practically relevant to our contexts.

\section{Low carbon diet}

This is under the discourse of a dietary cluster which emphasizes more on people checking on the amount of carbon in the foods they consume. Due to the advent of inorganic farming with its Genetically Modified Foods (GMOs), indeed the low carbon diet must be observed as some of the GMOs have long term health problems to those who consume them. A critical analysis into these foods reveals that, even the proper knowledge about what genetically modified foods are, is very much lacking in Zimbabwe let alone in Sub Saharan Africa. The other complex issue about the discourse of low carbon diet is the availability of the food itself. People cannot buy green especially when the food is not available on the market. This is Africa, where food is both scarce and not readily available on the market, therefore, to expect people to find out whether the food available is of high or low carbon content will be demanding a lot from them.

One cannot be expected to choose what type of food it is when they would have gone for days without eating something then, when the food is available you expect that individual to choose.

\section{Conclusion}

The thrust of this study was to do a critical analysis on the language of communicating information on climate change. From the critical discourse analysis of the linguistic aspects of climate change, it has been noted that scientists normally thrive on the use of metaphors, hedging techniques and compounding, among other things. Although there are some linguistic aspects that are inherent in the scientists' writing like 'collective pronouns', the researcher had to narrow down to only metaphors, hedging techniques and compounding as they are very prevalent in the magazines, technical journals and scientific briefings that the researcher analyzed.

The researcher also noted that the scientists, by continuing to communicate in technical language, they were using the gate keeping approach to protect their field. It has also been noted that by classifying people as 'US' and 'THEM', scientists would be communicating ideologically in order to save the interest of the developed countries at the expense of the developing countries. The use of metaphors, although it alerts people, if they don't have enough knowledge on climate change, they tend to panic. By using hedging techniques, scientists are reneging on responsibility; they do not want to be accountable for their actions and pronouncements.

The issue of bias has been established from their tone of communication as they fail to tell us the kind of punishment that will be mete to those countries that pollute the environment anyhow.The researcher has also noted that the compounding used, most of it is out of context with the Sub Saharan communities who are also supposed to be stakeholders in the fight against climate change. In the majority of countries of Sub Saharan Africa with specific reference to Zimbabwe, there is absence of intensive media in disseminating information on climate change. The media continue to impose a dark blanket on climate change issues and the people feel excluded. It has also been noted that the media is not doing much training to conscientize people on climate change. It is quite clear that, the media personnel need training first before they train others. The print media and electronic media do not classify the issue of climate change as a juicy beat as they are preoccupied about fighting the possible return of colonialism and imperialistic tendencies. The NGOs, both local and international are not doing enough to train communities about forest conservation and climate protection; instead they are pre-occupied about issues of governance and human rights abuses. The dilemma that ordinary Zimbabweans face is that they cannot link the natural disasters and other human activities to climate change; instead they link this to God's powers and punishments as well as myths. It has also been noted that the government is taking too long to make climate change part of the educational curriculum so that the children would grow up knowing the subject and be able to take it as part of their lives.

\section{Recommendations}

Finally, it must be incumbent upon all the leading lights of Africa in terms of climate change to try and take a leading role in communicating climate change issues instead of them being made to see climate change through the eyes and voices of the developed countries. Those who have comprehensive knowledge of climate change issues are a few academics who appear to own the knowledge and are sometimes prepared to share it for a fee. Also the book market is starved of books written by African authors. As a result we tend to rely on books written by experts from other countries that do not have comprehensive knowledge of our physical and social realities. These are books which do not share much on African experiences on climate change, as most of them talk about the Arctic Tundra being threatened, glaciers falling as well as snow storms pounding Europe. For this reason climate change has become more of a divider rather than a unifier that is why it has been described as the HIV scourge of the environment. 


\section{References}

[1]. P. Borchert. AFRICA Geographic: Our Overheating Planet (Devonshire Court, Cape Town, 2007).

[2]. Chivaura and G. Mararike. The human Factor Development in Africa (University of

[3]. Zimbabwe Publications, Mt. Pleasant, Harare, 1996).

[4]. C.T.A SPORE: Climate Change: Sharing Knowledge, Improving

[5]. Rural Livelihoods (South Africa, Cape Town, 2000).

[6]. L. Dow and G. Downing. Atlas of Climate Change. (Routledge, London, 2007).

I. Deutscher. What we say/what we do (Glenview, Illinois, Scott Foreman, 1973).

[7]. P. Eubanks. Written Communication. Sage Publications 16 (2), 1992, 18-32.

[8]. N. Fairclough. Critical Discourse Analysis (Longman, London, 1992).

[9]. N. Fairclough. Language and Globalization (Rutledge, New York, 2008).

[10]. N. Fairclough. Language and Power (Longman, London, 1992).

[11]. R. Henson. THE ROUGH GUIDE to Climate Change. The Symptoms

[12]. The Science. The Solutions (Rough Guides Ltd, London, 2006).

[13]. L. Hoepful. Research Methods in Languages (Harper and Row, London, 1996).

[14]. B. Levinson. Pragmatics (Cambridge University Press, Cambridge, 1983).

[15]. L. Mathews. Oxford Dictionary of Linguistics (Oxford University Press, Oxford, 1992).

[16]. G.A. Myers. The Pragmatics of Politeness in Scientific articles. Applied Linguistics, 1989, 10,-

[17]. $1-35$

A. Philips and H. Jorgensen. Discourse Analysis (Routledge, London, 2004).

F. Salager-Mayer. Hedges and Textual Communicative Function in Medical English written discourse. English for Specific Purposes, 13 (2), 1994, 149-170.

B. Toulmin. Climate Change in Africa (Zed Books, London, 2009).

T.Van Dijk. Principles of Critical Discourse Analysis. Discourse and Society, 4 (2); 2000, 249-283

\section{Internet Sources}

www.africageographic.com: accessed on 2012/01/17.

www.climatescience.gov : accessed on 2012/05/14

www.ipcc.ch : accessed on 2012/08/10

www.unstystem.org/ngls/documents/publications/voices.africa/numbers/vfa5.06.htm accessed on 2012/08/11 